\title{
Adaptive Leader-Follower Formation Control of under-Actuated Surface Vessels with Model Uncertainties and Input Constraints
}

\author{
Alireza Riahifard ${ }^{1}$, Seyyed Mohammad Hosseini Rostami ${ }^{2}{ }^{(D}$, Jin Wang ${ }^{3,4}$ (D) and Hye-Jin Kim ${ }^{5, *}$ \\ 1 Department of Electrical and Computer Engineering, Science and Research Branch, Islamic Azad University, \\ Tehran 1477893855, Iran; alireza.riahifard@srbiau.ac.ir \\ 2 Department of Electrical and Computer Engineering, Shiraz University of Technology, Shiraz 7155713876, \\ Iran; seyyed.mazandaran@gmail.com \\ 3 Hunan Provincial Key Laboratory of Intelligent Processing of Big Data on Transportation, School of \\ Computer \& Communication Engineering, Changsha University of Science \& Technology, Changsha 410004, \\ China; jinwang@csust.edu.cn \\ 4 School of Information Science and Engineering, Fujian University of Technology, Fuzhou 350118, China \\ 5 Business Administration Research Institute, Sungshin W. University, Seoul 02844, Korea \\ * Correspondence: hye-jinkim@hotmail.com; Tel.: +82-022-2870-097
}

Received: 29 December 2019; Accepted: 27 January 2020; Published: 5 April 2020

check for updates

The authors wish to make the following corrections to this paper [1].

In Figure 16, if you refer to the text of the paper [1], you notice that the second section $Y$-axis name of this figure is $\ln \left(\cosh e_{i}\right)$ and is different form the first section $Y$-axis name $\left(\tanh \left(e_{i}\right)\right)$. During the simulation in MATLAB, the names of both $Y$-axes were mistakenly written in a similar way, which we corrected it; thus, Figure 1 needs to be corrected as follows:
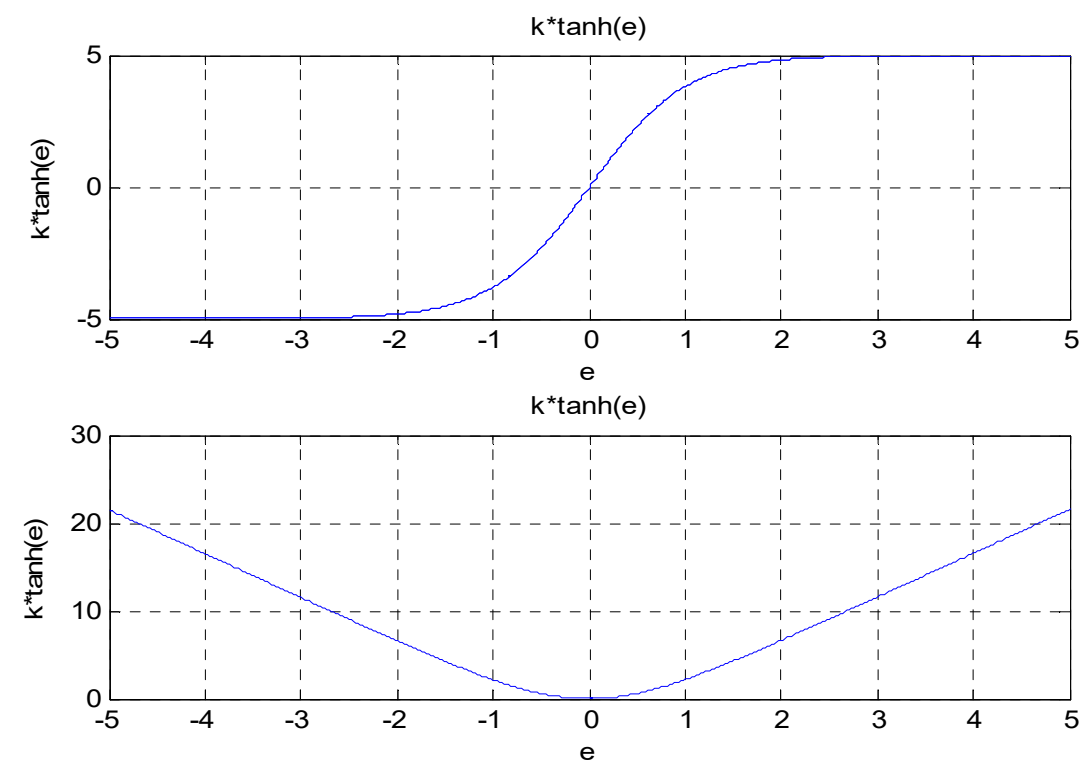

and should be replaced with 

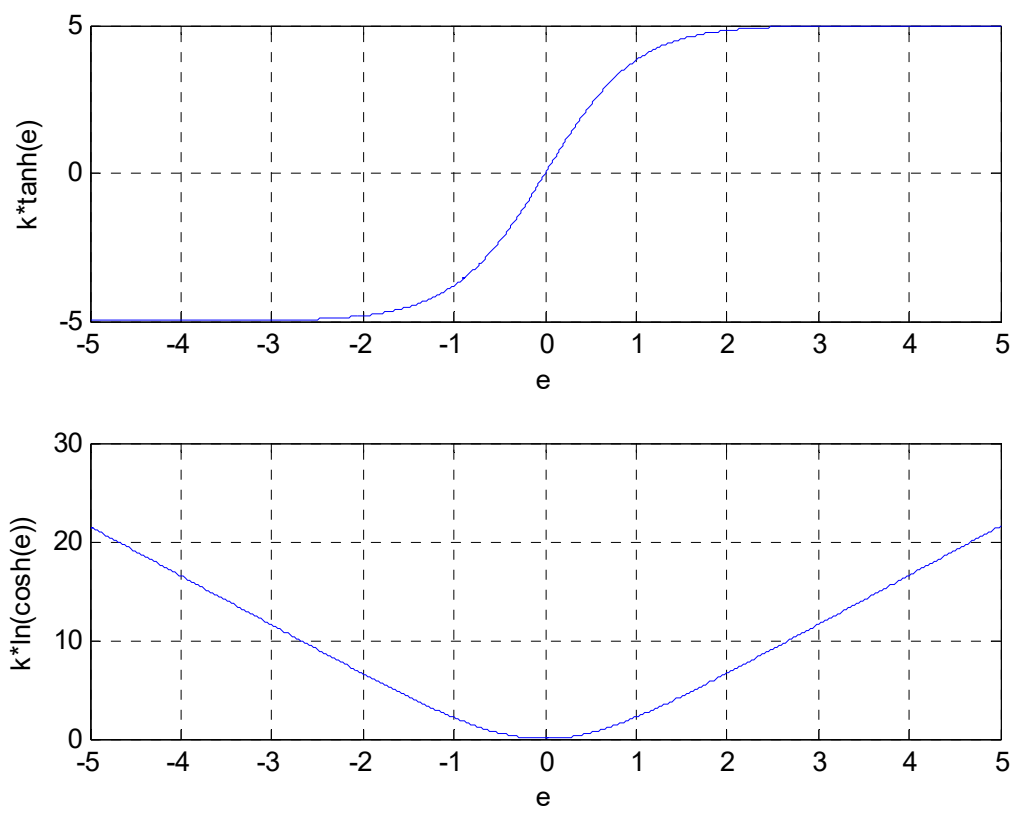

The authors apologize to the readers for any inconvenience caused by these changes. It is important to state that this correction does not affect our study's results, and involves no changes or modifications to the original data supporting our results. The original manuscript will remain online on the article webpage, with reference to this correction.

\section{Reference}

1. Riahifard, A.; Rostami, S.M.H.; Wang, J.; Kim, H.J. Adaptive Leader-Follower Formation Control of Under-actuated Surface Vessels with Model Uncertainties and Input Constraints. Appl. Sci. 2019, 9, 3901. [CrossRef]

(C) 2020 by the authors. Licensee MDPI, Basel, Switzerland. This article is an open access article distributed under the terms and conditions of the Creative Commons Attribution (CC BY) license (http://creativecommons.org/licenses/by/4.0/). 